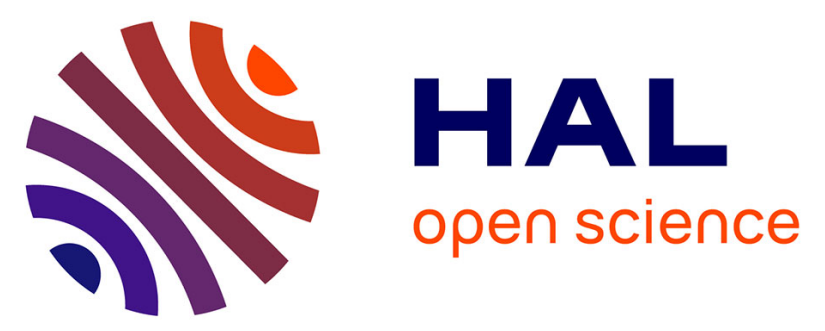

\title{
IGLOO3D Computations of the Ice Accretion on Swept-Wings of the SUNSET2 Database
}

\author{
Emmanuel Radenac, Hélène Gaible, Hervé Bézard, Philippe Reulet
}

\section{To cite this version:}

Emmanuel Radenac, Hélène Gaible, Hervé Bézard, Philippe Reulet. IGLOO3D Computations of the Ice Accretion on Swept-Wings of the SUNSET2 Database. SAE International Conference on Icing of Aircraft, Engines and Structures, Jun 2019, Minneapolis, United States. 10.4271/2019-01-1935 . hal-02859982

\section{HAL Id: hal-02859982 \\ https://hal.science/hal-02859982}

Submitted on 8 Jun 2020

HAL is a multi-disciplinary open access archive for the deposit and dissemination of scientific research documents, whether they are published or not. The documents may come from teaching and research institutions in France or abroad, or from public or private research centers.
L'archive ouverte pluridisciplinaire HAL, est destinée au dépôt et à la diffusion de documents scientifiques de niveau recherche, publiés ou non, émanant des établissements d'enseignement et de recherche français ou étrangers, des laboratoires publics ou privés. 


\title{
IGLOO3D computations of the ice accretion on swept-wings of the SUNSET2 database
}

\author{
Emmanuel Radenac, Helene Gaible, Herve Bezard, and Philippe Reulet
}

ONERA / DMPE Université de Toulouse

\begin{abstract}
In the framework of the SUNSET2 program, ice accretion numerical tools were assessed against experimental data. The database of ice shapes was generated on CRM-like swept-wings in NASA's IRT wind tunnel. This paper discusses calculations of ice accretion on some cases of this database with the ONERA's 3D ice accretion suite, called IGLOO3D. This tool is described in the first part of the paper. It is designed to couple three codes which solve the air flow (Navier-Stokes solver), the trajectories of water droplets (Eulerian or Lagrangian solver) and the ice accretion (Messinger approach), respectively. The coupling is made in a one-way manner by exchanging CGNS files. IGLOO3D is modular and makes it possible to couple any code as long as it reads and produces CGNS files.
\end{abstract}

The ice thickness predicted by IGLOO3D is compared against the experimental ice shapes and the LEWICE3D results. Several issues are discussed, especially regarding the bulk ice density and the effect of the convective transfer in the energy balance. The convective transfer is strongly influenced by roughness. Several approaches are shown in the present paper regarding the modelling of the effects of roughness. First, the baseline approach consists of employing the Makkonen integral model with a uniform equivalent sand-grain roughness height. Second, the heat transfer coefficient is inferred from Navier-Stokes computations with a model for roughness effects. The distribution of roughness properties is inferred from a dedicated ice shape of the SUNSET2 database. This approach is quite new for 3D ice accretion computations, which raises some new issues discussed in the present paper.

\section{Introduction}

NASA, FAA, ONERA, as well as the Universities of Illinois, Virginia and Washington and the Boeing company are working on a research program, called SUNSET2, which aims to improve the understanding and ability to model ice accretion and the resulting aerodynamic effect on full-scale, 3D swept wings. Among other activities, ice accretion measurements were made on a swept wing in the NASA Icing Research Tunnel (IRT) and ice accretion tools are improved and assessed on this database. The tested wing was derived from the Common Research Model (CRM) wing which led to the definition of three shapes corresponding to inboard, semi-span and outboard sections of the wing. Three sets of data are thus available for different icing conditions [1].

Page 1 of 10
Regarding 3D ice accretion modelling, ONERA is developing an ice accretion suite called IGLOO3D. This tool is designed to couple three codes which solve the air flow (Navier-Stokes solver), the trajectories of water droplets (Eulerian or Lagrangian solver) and the ice accretion (Messinger approach), respectively.

IGLOO3D was validated against its 2D counterpart IGLOO2D in a previous paper [2]. First computations on the SUNSET2 database were also shown in [2]. The inboard model was employed and the article mainly focused on the preliminary Navier-Stokes computations.

The present paper focuses on ice accretion computations on both midspan and inboard models. Since the ice shape can only be predicted through a one-step approach, it is unlikely that the complex 3D ice shapes can be predicted by IGLOO3D. The full scallop cases will thus not be addressed in this paper. Several models will be crosscompared regarding the modelling of roughness effects. The results of IGLOO3D will also be compared against the experimental results and LEWICE3D results presented in [3].

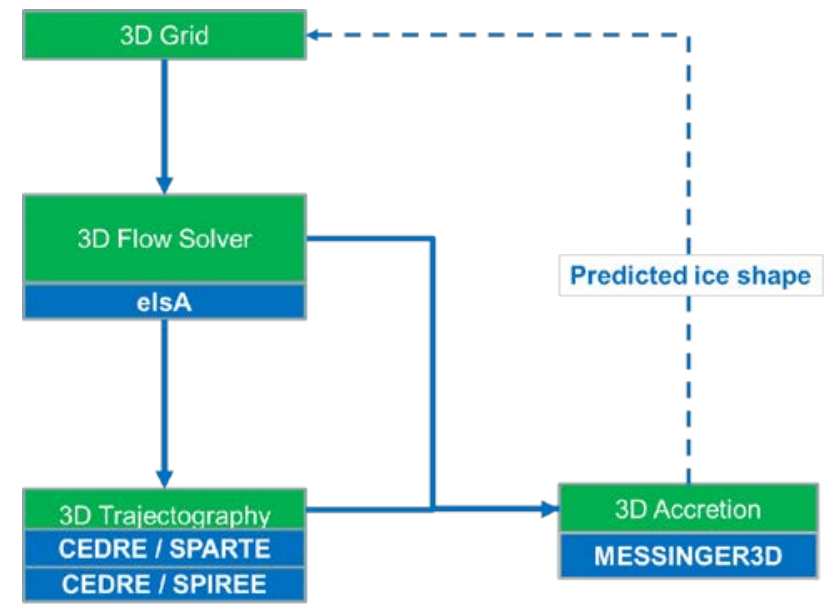

Figure 1 IGLOO3D flowchart

\section{Presentation of the 3D icing suite IGLOO3D}

ONERA's 3D icing suite IGLOO3D is described in Figure 1. First, the $3 \mathrm{D}$ clean geometry is meshed with a mesh generator, such as ICEM-CFD for the current study. Then the aerodynamic field is computed with a gas solver (here, the ONERA's structured code elsA 
[4]). Several parameters are expected from this code. First, volume data are provided to the trajectography solver (velocity, pressure and temperature). Second, surface data are given to the accretion solver: pressure, temperature, skin friction, convective transfer coefficient $\mathrm{h}_{\mathrm{tc}}$.

Regarding the trajectography computation, several solvers can be used. For instance, the Eulerian solver SPIREE or the Lagrangian solver SPARTE, both integrated in the ONERA's platform CEDRE, can be employed. SPIREE was used for the present paper.

Finally, MESSINGER3D is the classical Messinger model solver used for ice accretion in IGLOO3D. This code solves the steady-state mass and energy balance on the surfaces which are divided into control volumes.

It must also be noted that all the codes involved in IGLOO3D exchange data in a one-way manner via CGNS files as prescribed in the French research project ECLIPPS.

$\mathrm{h}_{\mathrm{tc}}$ is a major parameter for ice accretion calculations. It is usually not a direct output of the fluid solver. Several approaches exist. The most common approach in icing suites consists of simplified integral method approaches, accounting for the effects of roughness (Makkonen model [5]). $\mathrm{h}_{\mathrm{tc}}$ is obtained via the Stanton number St:

$\mathrm{h}_{\mathrm{tc}}=$ St $\rho u c_{p}$,

where $\rho$ is the air density, $c_{p}$ the specific heat capacity at constant pressure for air and $u$ the velocity outside of the boundary layer.

$S t=\frac{C_{f} / 2}{\operatorname{Pr}_{t}+\sqrt{C_{f} / 2} / S t_{k}}$,

$\mathrm{Pr}_{\mathrm{t}}$ is the turbulent Prandtl number and $S t_{k}=1.92 \mathrm{Re}_{\mathrm{k}}^{-0.45} \mathrm{Pr}^{-0.8}$. The roughness Reynolds number, $\operatorname{Re}_{k}=\frac{\rho u_{\tau} k_{s}}{\mu}$, is defined with the equivalent sand-grain roughness height $k_{s}$, the viscosity of air outside of the boundary layer $\mu$ and the friction velocity $u_{\tau}$. Besides, $C_{f}$ is the skin friction coefficient on a rough wall, given by:

$$
\frac{C_{f}}{2}=\frac{0.168}{\left(\ln \left(864 \frac{\theta}{k_{s}}+2.568\right)\right)^{2}}
$$

where $\theta$ is the momentum thickness.

As described in [2], since, here, the Navier-Stokes solver is elsA, there are several possibilities. The approach which gives the most similar results to IGLOO2D consists of using the momentum thickness given by elsA to feed the $h_{t c}$ model. This approach will be used in the present paper as a baseline model. Here smooth-wall elsA computations are expected. It is also possible to feed directly the $h_{t c}$ model with the skin friction coefficient produced by elsA (rough-wall computations are expected).

Finally, it is also possible to use directly the heat flux produced by elsA. Rough-wall computations are thus expected and the specific model defined by Aupoix was employed to that end [6]. Then it is

Page 2 of 10 possible to perform two elsA computations with different wall temperatures. $h_{t c}$ comes from the linearization of the heat fluxes obtained in the two calculations.

The classical Messinger model is employed and the liquid water is assumed to flow along the friction lines. The main outputs of the model are the amount of freezing water and the ice-water-system temperature in each control volume. The ice shape can thus be built by specifying the ice bulk density. A classical model can be used like in $2 \mathrm{D}$ icing suites $[7,8]$, or the ice density can be manually adjusted.

It is also worth mentioning that, up to now, IGLOO3D is usable only in a simple predictor mode: the predicted ice shape over the clean geometry is produced.

\section{IGLOO3D computations}

\section{Database investigated}

During the SUNSET2 project, an ice-shape database on swept wings was generated at NASA's icing wind tunnel IRT. The studied airfoil was the so-called CRM65 wing (65\%-scale Common Research Model). To investigate ice accretion in the IRT, three sections of the CRM65 wing were selected. The so-called inboard model represents the station closest to the wing root, the outboard model is the station closest to the wing tip and a midspan model was also created from an intermediate station. The interested reader will find further information in references [1] and [3]. The two sections on which IGLOO3D was used are the inboard and midspan sections. The conditions of the IRT test were reproduced as accurately as possible for the IGLOO3D computations. The installation of the wing (and flap) in the wind tunnel was thus reproduced fairly accurately. For instance, Figure 2 shows the grid made with ICEM-CFD for the midspan model (multi-block structured grid composed of 24 Mcells). The icing conditions provided in Table 1 and Table 2 were also employed. They are representative of the test conditions. Regarding droplet injection, it should be noted that a 10-bin distribution representative of IRT injection was used [9].

Table 1 shows the icing conditions investigated with IGLOO3D regarding the inboard model. As regards the midspan model, the conditions of Table 2 were retained. Only cases for which the spanwise ice structure was not too developed were investigated with IGLOO3D. No scallop is indeed expected to be captured with the simple predictor computations allowed by IGLOO3D. 


\begin{tabular}{|c|c|c|}
\hline Run ID & TG2406 & TG2426 \\
\hline Ice shape & Streamwise / Rime & Incomplete Scallop \\
\hline $\mathrm{P}(\mathrm{Pa})$ & 96110 & 96110 \\
\hline $\mathrm{T}(\mathrm{K})$ & 253.05 & 259.65 \\
\hline $\mathrm{LWC}\left(\mathrm{g} / \mathrm{m}^{3}\right)$ & 0.6 & 1.0 \\
\hline $\mathrm{MVD}(\mu \mathrm{m})$ & 25 & 25 \\
\hline $\mathrm{V}(\mathrm{m} / \mathrm{s})$ & 66.88 & 66.88 \\
\hline $\mathrm{M}$ & 0.210 & 0.207 \\
\hline$\Delta \mathrm{t}(\mathrm{s})$ & 1380 & 1740 \\
\hline
\end{tabular}

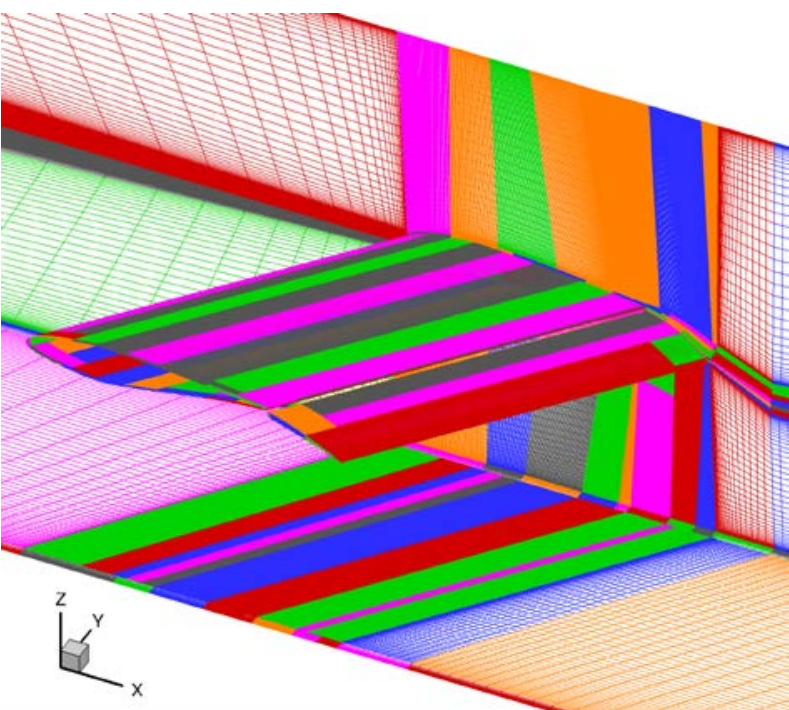

Figure 2 Structured multi-block grid generated with ICEM-CFD for the midspan model

\section{Roughness characterization}

Among the SUNSET2 ice-shape database tests, some tests were performed with very short exposure times to the icing cloud. These tests produced very thin ice shapes, representative of the roughness developing on iced surfaces. It was possible to use these measurements to estimate the input parameters of Aupoix's roughness model. Especially, for the midspan model, in glaze-ice conditions, the icing conditions of the TH2462 case were used. Compared to the TH2432 case, the same conditions were used except for accretion time, $150 \mathrm{~s}$, and static temperature, $264.62 \mathrm{~K}$. The icing conditions were thus very similar to the ones used in TH2432 and TH2458 tests. The difference on temperature becomes more significant for case TH2514.

The three input parameters of Aupoix's roughness model are the equivalent sand-grain roughness height, $k_{s}$, a mean roughness height, $k_{\text {moy }}$ and a non-dimensional corrected wetted surface $S_{\text {corr }}$ [6]. Figure 3 and Figure 4 show the spatial distribution of these parameters along the ice shape, where $s=0$ at the airfoil leading edge in the original frame. To derive the parameters, a statistical processing was done on samples including all data measured over the entire span of the measured ice shape. Additionally, $k_{s}$ was computed from Flack and Schultz formula [10]. The distributions of Figure 3 and Figure 4 were projected on the surface grid to provide the inputs of Aupoix's model in elsA computations. As often observed [11], the roughness height is lower in the vicinity of the separation line $(s \approx-0.03 \mathrm{~m})$ : a reduction is observed for $k_{s}, k_{\text {moy }}$ and $S_{\text {corr }}$. A slight increase is observed downstream on pressure side $(s<-0.03 \mathrm{~m})$ and a larger increase on suction side $(s>-0.03 \mathrm{~m})$. It is worth mentioning that $\mathrm{k}_{\mathrm{s}}$ is quite large everywhere, even at the separation line where $\mathrm{k}_{\mathrm{s}}$ is around $1.5 \mathrm{~mm}$. $\mathrm{k}_{\mathrm{s}}=1.5 \mathrm{~mm}$ is indeed the maximum value allowed in ONERA's implementation of the Makkonen model. By the way, the Makkonen model was used here with $\mathrm{k}_{\mathrm{s}}=1.5 \mathrm{~mm}$.

It is worth mentioning that the same kind of statistical processing was employed on the fully-developed ice shapes especially to derive the 
average ice shapes shown in Figure 7, Figure 8, Figure 9, Figure 10 and Figure 13 (arithmetic average in spanwise samples).

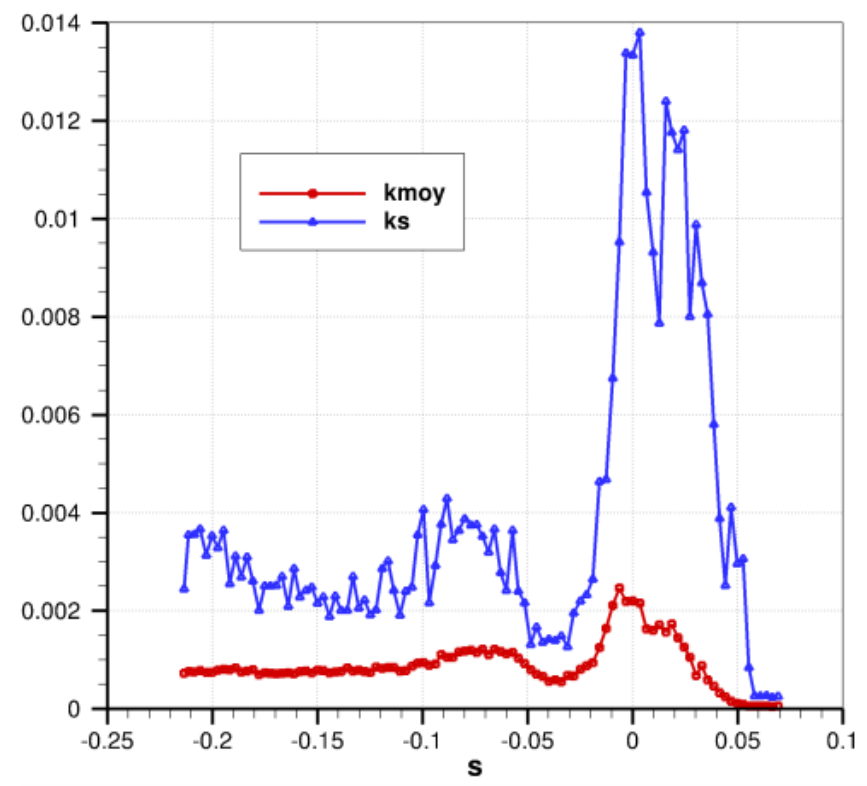

Figure 3 Distribution of equivalent sand-grain roughness height $k_{s}$ and mean roughness height $k_{\text {moy }}$ derived from TH2462 ice shape measurements

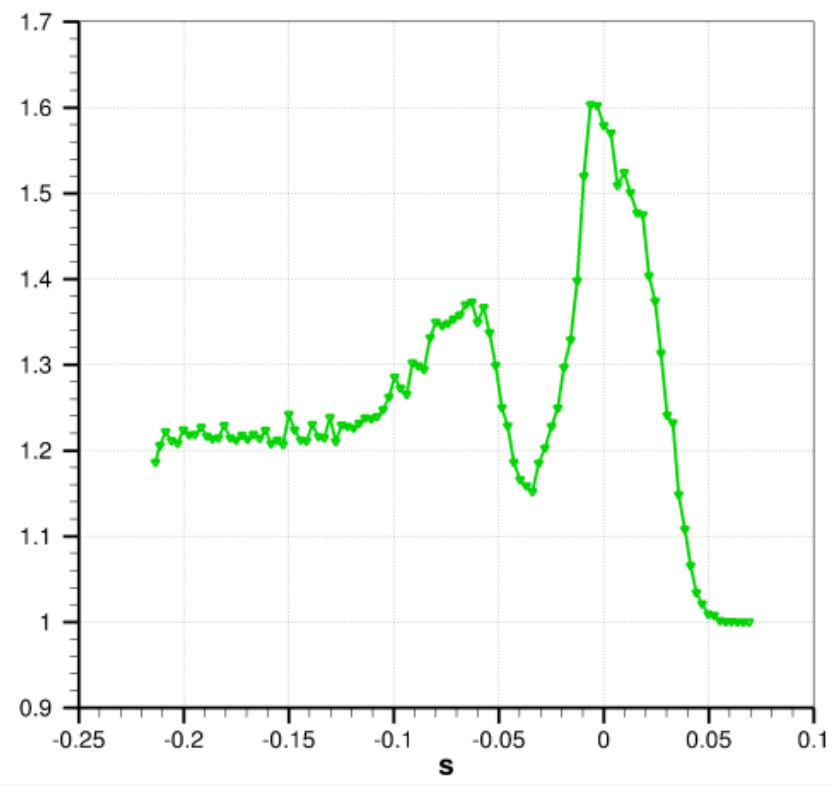

Figure 4 Distribution of non-dimensional corrected wetted surface $S_{\text {corr }}$ derived from TH2462 ice shape measurements

\section{IGLOO3D Results with standard Makkonen model}

Two kinds of experimental data were mainly available for validation. To ensure that the aerodynamic calculations (performed with elsA) were correct, the pressure distribution was measured on the airfoil. Figure 5 shows a good agreement between the experimental results and those of elsA (for several rough-wall models).

Page 4 of 10

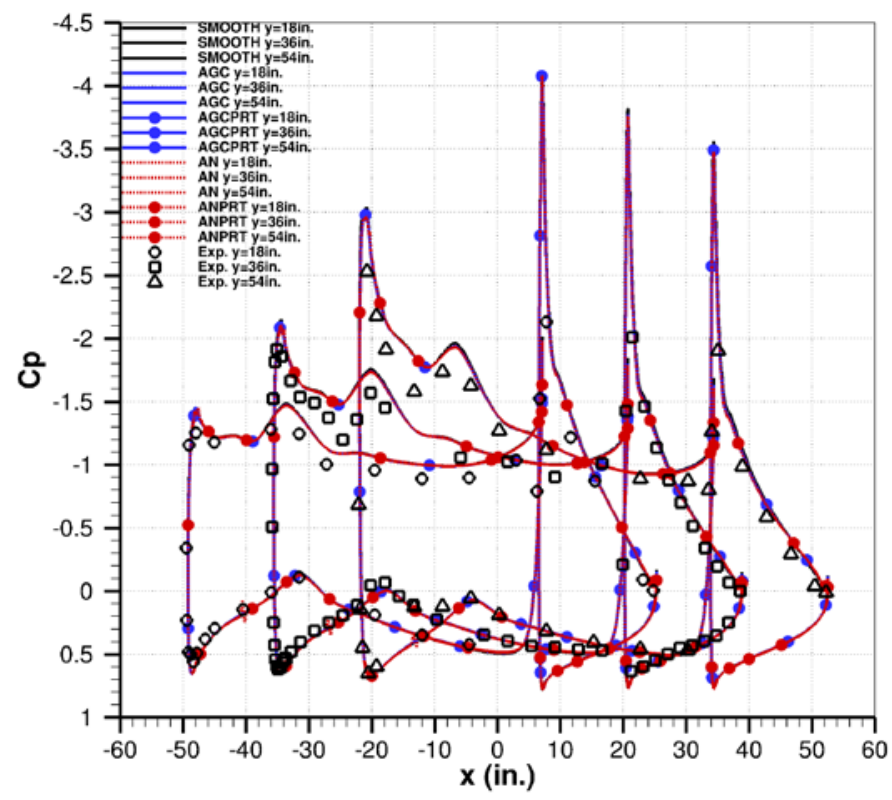

Figure 5 Pressure coefficient along cuts at $y=18$ in., $y=36$ in. and $y=54$ in.. Here $T_{\text {wall }}=263.15 \mathrm{~K}$ and $\mathrm{T}=259.55 \mathrm{~K}$. AGC: Aupoix-Grigson-Colebrook model [12], AN: Aupoix-Nikuradse model [12], PRT: Aupoix's correction for rough-wall heat transfer [6]

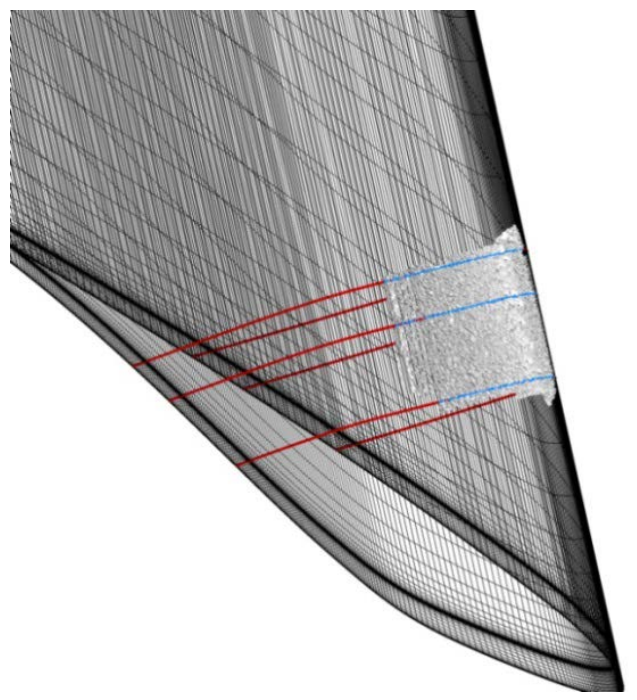

Figure 6 Three cuts along which IGLOO3D results are plotted. TG2426 testcase.

The second data available for validation is the measured ice shapes. For the following plots, three cuts were employed as shown in Figure 6. An example of measured iced surface is also given in Figure 6. The iced surface is also plotted on the following figures as a set of points which give an idea of the overall ice shape and the "dispersion" mainly implied by the spanwise structure. Finally, LEWICE3D results available in reference [3] were also added.

The standard Makkonen model was first employed for the IGLOO3D computations on all the test-cases of Table 1 and Table 2.

Figure 7 shows the ice shapes given by IGLOO3D on the two testcases of the inboard database. Both cases were predicted rime ice by IGLOO3D (there is no runback), which was not expected for TG2426 
case. Since roughness mainly affects the convective heat transfer which in turn only affects glaze-ice shapes, all the approaches for roughness modelling gave the same results. Besides, it is worth mentioning that the agreement with the experimental results requires the use of a manually-adjusted ice density $\left(450 \mathrm{~kg} / \mathrm{m}^{3}\right)$. However, the results given by both LEWICE3D and IGLOO3D are very similar (the same adjusted ice density was required for LEWICE3D).

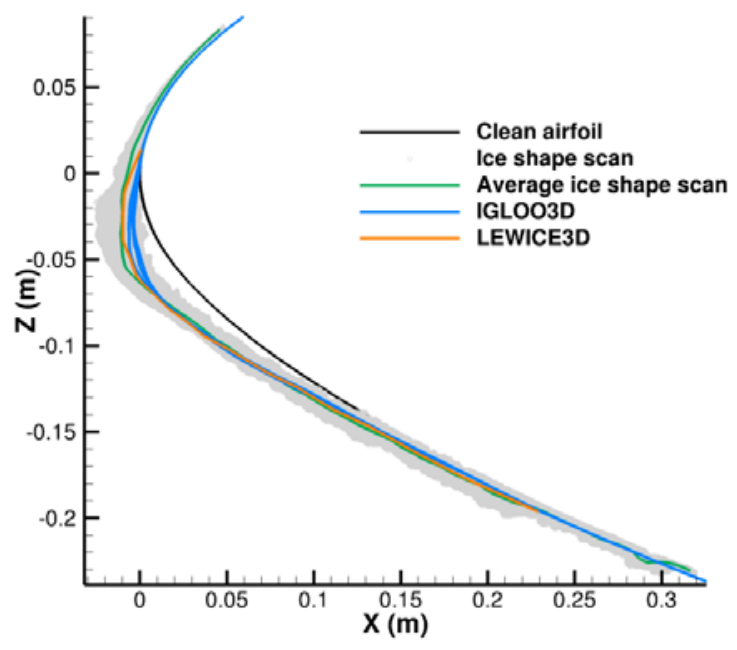

(a) TG2406 case

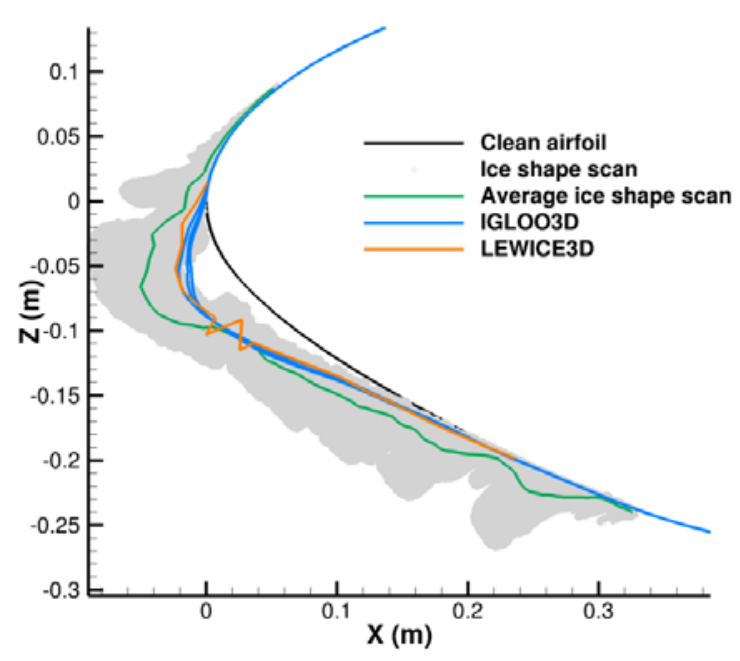

(b) TG2426 case

Figure 7 Ice shapes for inboard cases, computations with $\rho_{\text {ice }}=450 \mathrm{~kg} / \mathrm{m}^{3}$

The midspan database was more thoroughly investigated with IGLOO3D. As in the inboard case, the rime case (TH2439) is rather well captured in terms of average ice shape, as long as $\rho_{\text {ice }}=$ $450 \mathrm{~kg} / \mathrm{m}^{3}$ (Figure 8(a)). More generally, it is worth noting that the numerically-predicted ice shape is more similar to the average shape than to the envelope of the experimental points, which raises the question of the representativeness of the predicted ice shapes in terms of aerodynamic effects. Besides, LEWICE3D is a little better than IGLOO3D in terms of ice limits. The explanation for this is the slight differences in collection efficiency (Figure 11(a)). This may be due to differences in grid refinement and slight differences in aerodynamic solutions. The ice is however too thick at the separation line, which may reflect the fact that a uniform ice density is not correct and a proper model should be developed. The standard correlations based on Macklin's parameter, used in most 2D icing suites, may have to be reshaped due to significant sweep-angle effects.

The incomplete-scallop case (TH2432) is predicted as rime-ice by the IGLOO3D calculation (Figure 8(b)), which was also observed for the inboard geometry. LEWICE3D apparently provides a runback area in the vicinity of the separation line. This may be due to the mesh refinement and differences in laminar and turbulent regime occurrence at the leading edge. It is also consistent with the fact that there is more water impingement with LEWICE3D (Figure 11(a)). Anyway, the separation line area is not well calculated by either of the two codes. The issue of uniform bulk ice density may be again part of the explanation. Further downstream, both codes provide an ice thickness that is fairly representative of the experimental shape.

More surprisingly, case TH2458 is still expected to be rime-ice by IGLOO3D (except at one point), while 2 typical horns of a glaze-ice shape appear more and more clearly on the results of LEWICE3D (Figure 9(a)). The agreement with the mean ice shape (which is difficult to comment since $\rho_{\text {ice }}$ was adjusted manually) in the downstream area seems more dependent on runback for this case. LEWICE3D is indeed a little better on the upper part of the ice shape. Again, the difference between IGLOO3D and LEWICE3D may be partly due to the mesh refinement, the laminar-turbulent transition and the slightly larger quantity of impinging water. The heat transfer coefficient produced by LEWICE3D may also be smaller than the one used by IGLOO3D. It was indeed possible to compare the heat transfer coefficients of LEWICE3D and IGLOO3D, for case TH2439. It is worth mentioning that IGLOO3D provides very similar $\mathrm{h}_{\mathrm{tc}}$ for all conditions. The airflow velocity is indeed the same and the roughness height is the same for all inboard cases. On the other hand, LEWICE3D's $h_{t c}$ changes for all the cases because the roughness height is adapted according to icing conditions. However, it is possible to draw some conclusions from TH2439 test-case with implications for all the cases. Figure 11(b) shows that $h_{t c}$ is indeed lower for LEWICE3D near the separation line. IGLOO3D provides a turbulent regime here while it is possible that LEWICE3D provides a laminar zone at this location. Further downstream, the behavior may be linked to TH2439 test-case but it shows that IGLOO3D can predict a lower $h_{t c}$ than LEWICE3D. Even if this is also the case for TH2458 test-case, neither code predicts runback anymore and the discrepancy on $\mathrm{h}_{\mathrm{tc}}$ has no effect on the ice shape.

Regarding case TH2514 (Figure 9(b)), the glaze-ice regime was well captured by both codes. LEWICE3D predicts two horns again while IGLOO3D provides a thicker shape along the separation line. In addition, the difference between the ice shapes predicted by IGLOO3D along the three sections of interest (shown in Figure 6) is larger than for the other test-cases. This seems to be an effect of runback, which was not observed in the rime-ice cases. In addition, with $\rho_{\text {ice }}=450 \mathrm{~kg} / \mathrm{m}^{3}$, the predicted ice shape is too thick compared to the average shape for both codes. This time, the shape obtained without adjusting $\rho_{\text {ice }}$ is more representative of the average shape, although always underestimating the thickness (Figure 10). On the basis of the cases studied in this paper, it seems that the $450 \mathrm{~kg} / \mathrm{m}^{3}$ bulk ice density is rather correct for rime cases and maybe to take into account important spanwise structures. 


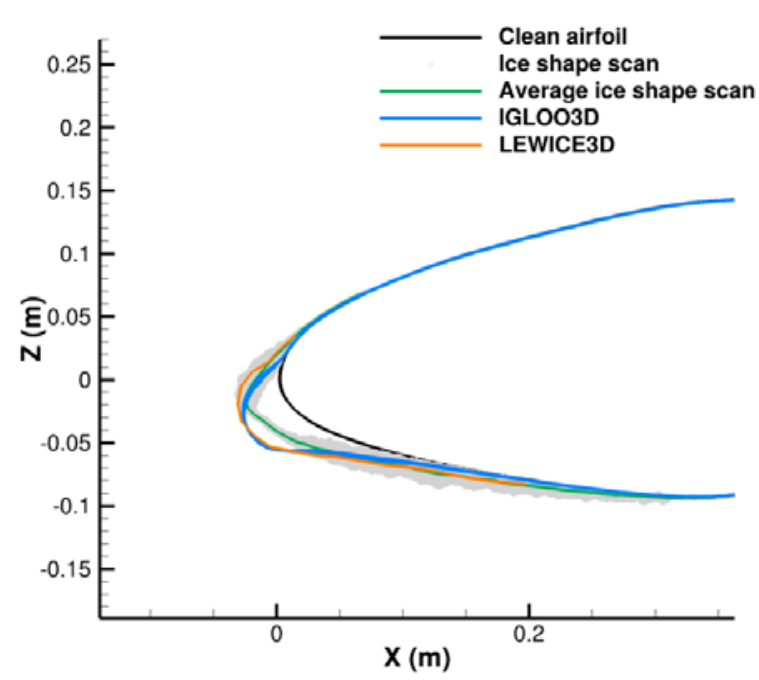

(a) TH2439 case

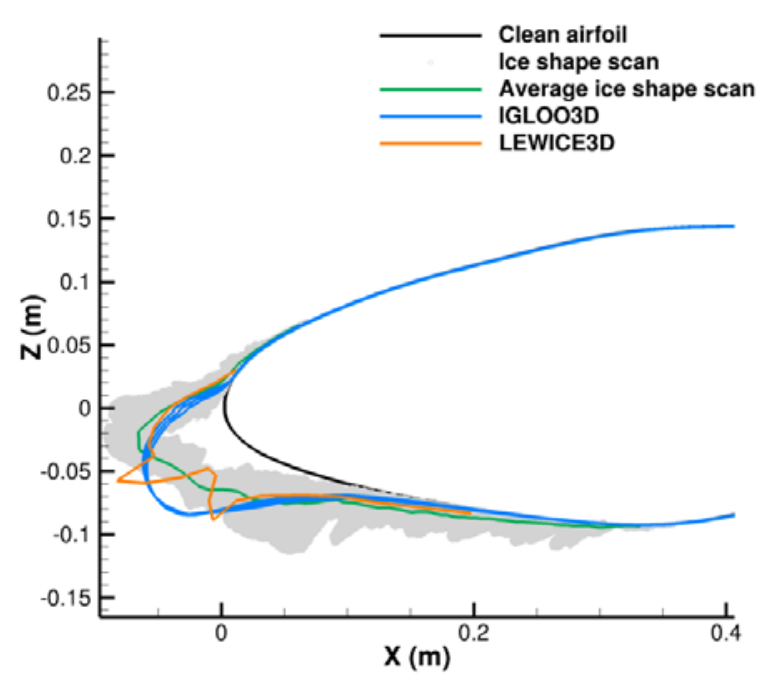

(b) TH2432 case

Figure 8 Ice shapes for colder midspan test-cases, computations with $\rho_{\text {ice }}=$ $450 \mathrm{~kg} / \mathrm{m}^{3}$

Page 6 of 10

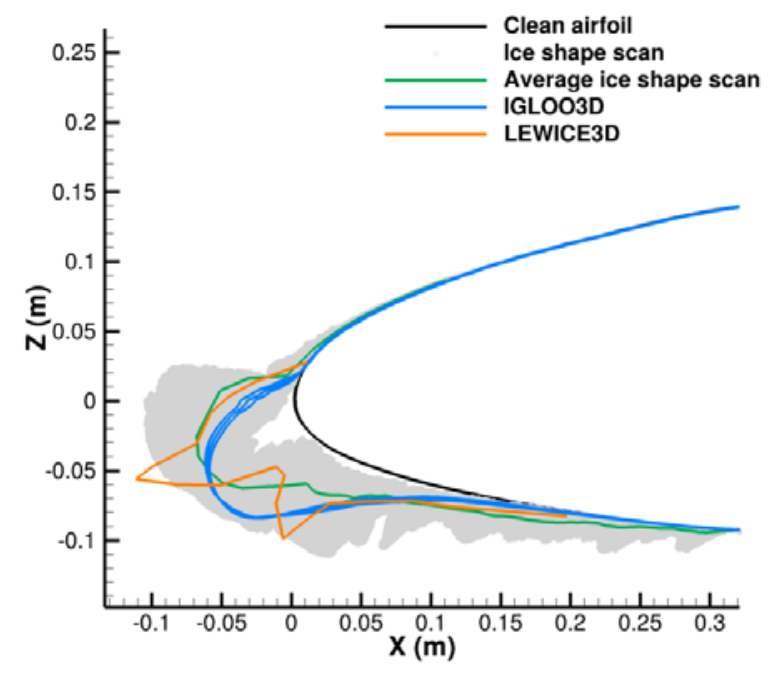

(a) TH2458 case

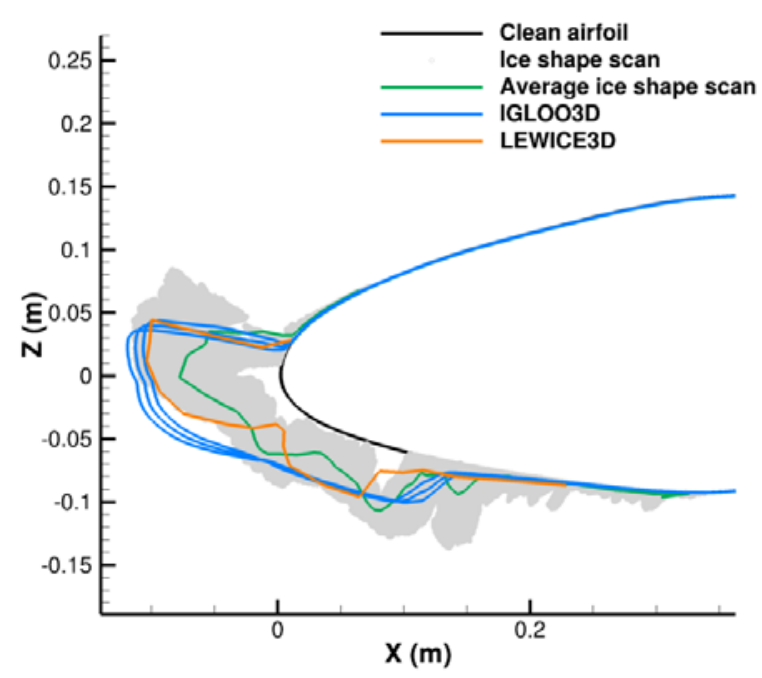

(b) TH2514 case

Figure 9 Ice shapes for "small-gap” and WB33 Direct Appendix C midspan test-cases, computations with $\rho_{\text {ice }}=450 \mathrm{~kg} / \mathrm{m}^{3}$ 


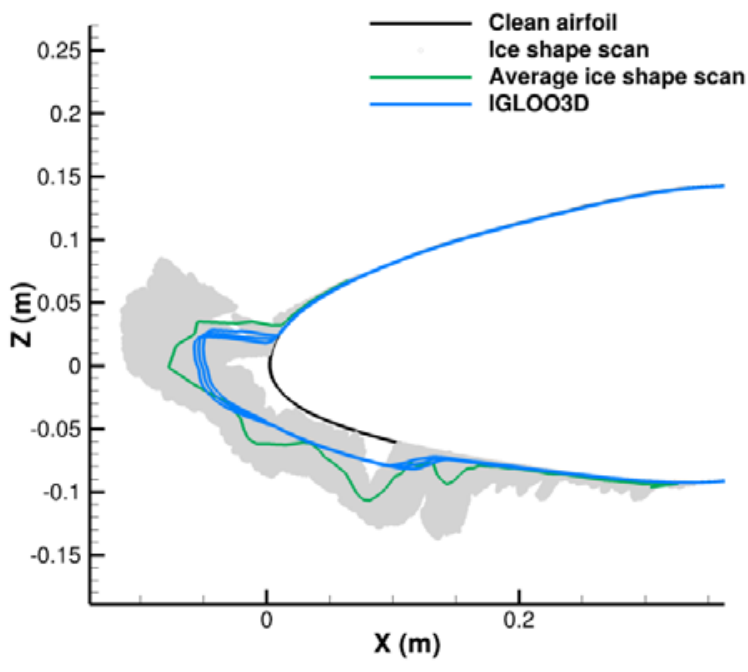

Figure 10 Ice shapes for TH2514 case (WB33 Direct Appendix C midspan) test-cases, computations with classical $\rho_{\text {ice }}$ model

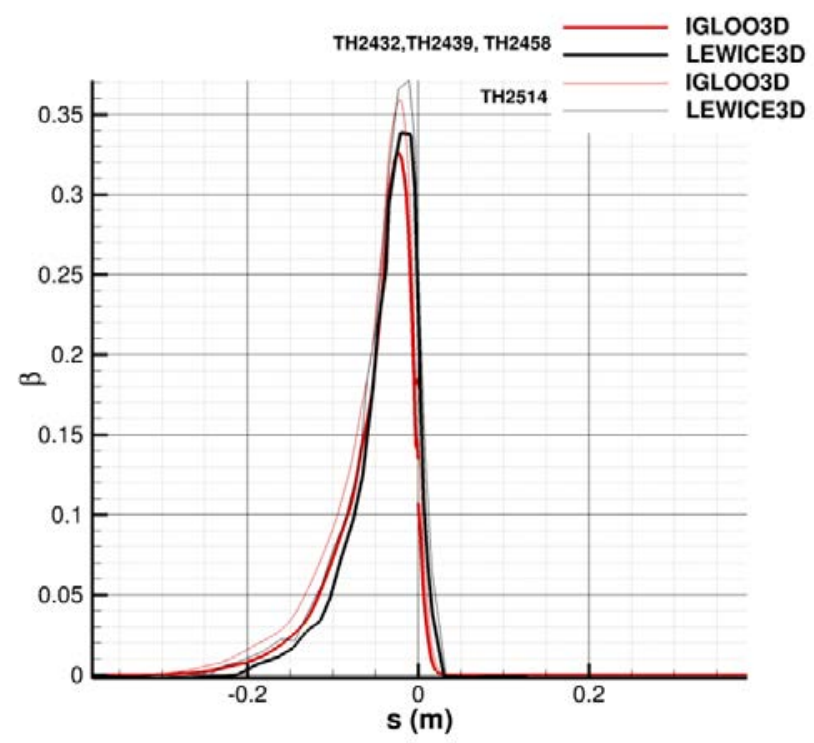

(a) collection efficiency, MVD=25 $\mu \mathrm{m}$ (TH2432, TH2439, TH2458) and MVD=28 $\mu \mathrm{m}(\mathrm{TH} 2514)$

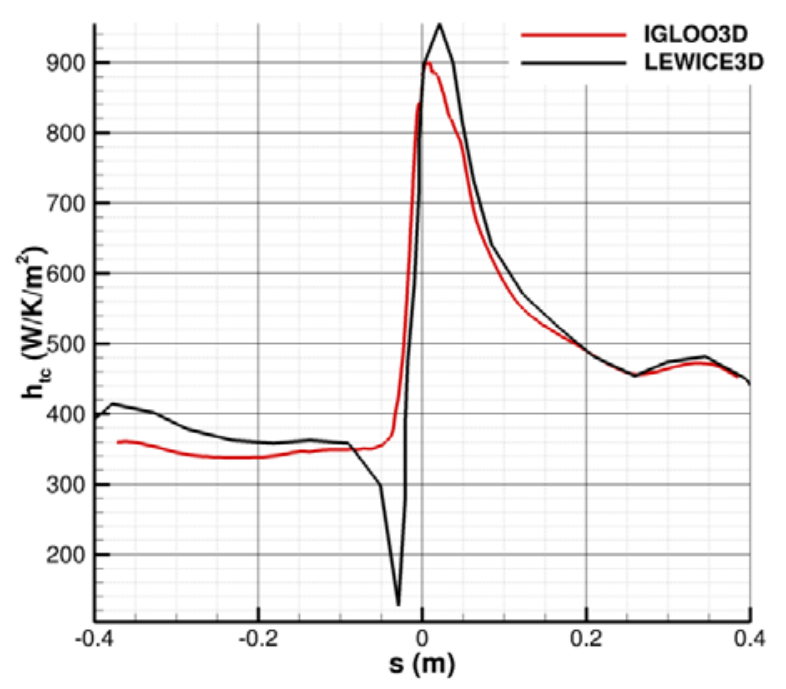

(b) heat transfer coefficient, TH2439

Figure 11 Comparison between IGLOO3D and LEWICE3D regarding collection efficiency and heat transfer coefficient. LEWICE3D results digitized from [3]

\section{IGLOO3D results with Aupoix's roughness model}

As shown in the previous section, TG2426, TH2432 and TH2458 cases are predicted rime-ice by IGLOO3D. The predicted ice is therefore expected to be too cold and with too few runback. One possible reason for this problem is that the convective exchange would be too strong. It was therefore attempted to replace the classic Makkonen model by Aupoix's model in the present section, which will actually make it possible to identify areas of investigation for the use of this model for ice-accretion calculations. However, for example, in the TH2458 case, the ice shape was not improved with Aupoix's model. Although the roughness is lower in the vicinity of the separation line than further downstream as noted previously, the convective exchange is even larger with the new model (Figure 12(a), $z \approx-0.03 \mathrm{~m}$ ). The issue may be linked to the fact that the characterized $k_{s}$ is actually rather large everywhere, which may be an issue with the formula used to compute $k_{s}$. The difference in behavior may also be partly due to the fact that the Makkonen model is used here as if there were no 3D effect. The overall difference between the two models may also be due to the fact that Aupoix's model was developed on the basis of zero-pressure-gradient flows with a uniform roughness size. As a result, there is even less runback with Aupoix's model. Finally, a significant decrease in $\mathrm{h}_{\mathrm{tc}}$ would be expected by enforcing a laminar area around the separation line, which was not made here. 


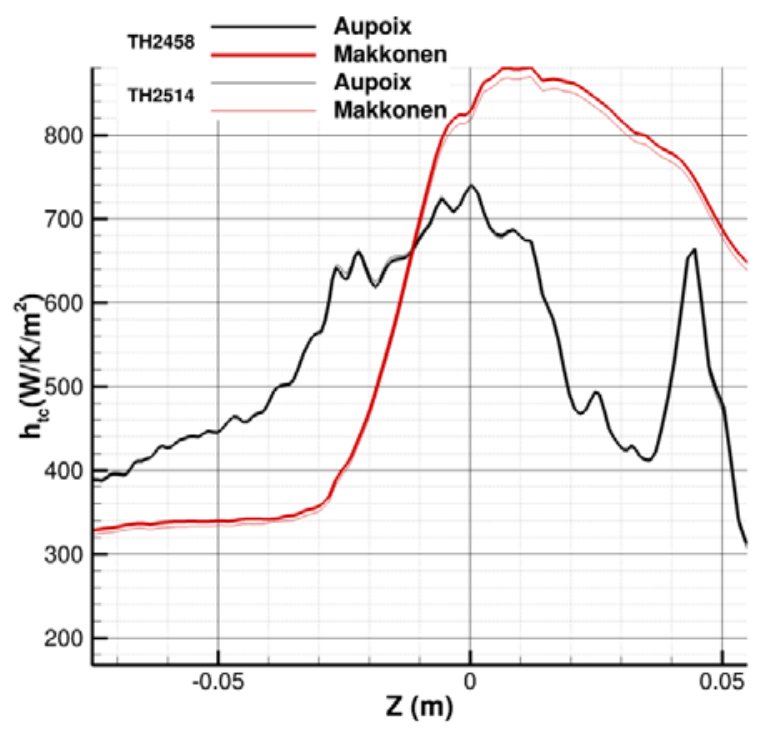

(a) heat transfer coefficient

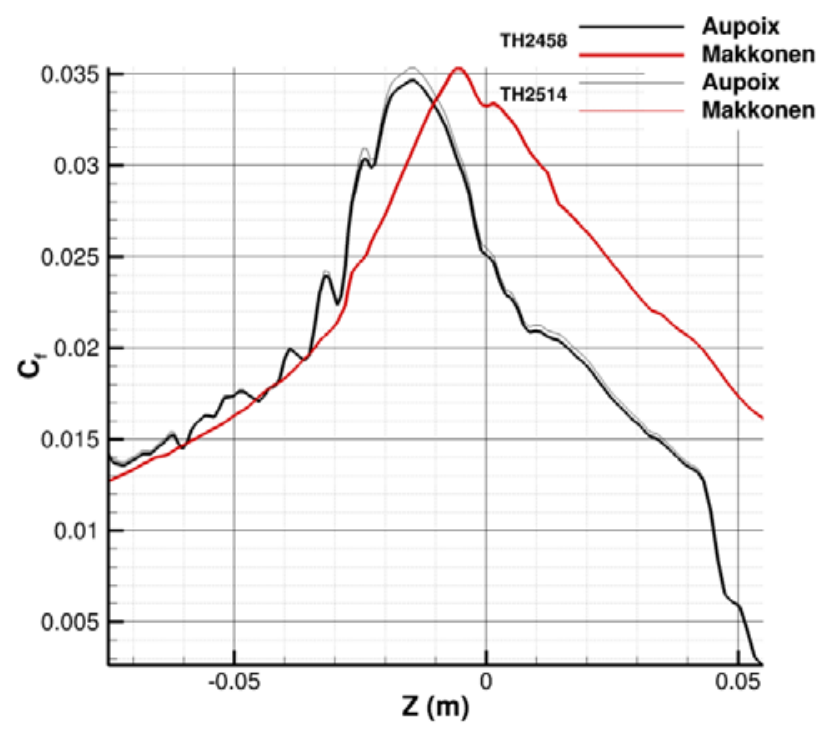

(b) skin friction coefficient

Figure 12 TH2458 and TH2514 cases: heat transfer coefficient and skin friction coefficient predicted by IGLOO3D

The heat transfer coefficients are almost identical for TH2458 case and TH2514 case (Figure 12(a)). The ice is thus also colder with the new model in the vicinity of the separation line for TH2514 case. There is thus fewer runback. On the contrary, $\mathrm{h}_{\mathrm{tc}}$ becomes smaller with the new model than with the Makkonen model in the upper part of the wing (more precisely for $z>-0.01 \mathrm{~m}$ ), where there is fewer ice. It was not expected because $k_{s}$ is rather large there. However, it must also be noted that the skin friction is also predicted smaller by Aupoix's model than by the Makkonen model in this area (Figure 12(b)). There may be two explanations for this. First, the Makkonen and Aupoix models may not be suitable for swept-wing flows. Second, the characterization of the input parameters of Aupoix's model may not yet be well understood. It is still unclear how the competition between higher $k_{s}$ and lower friction affects $\mathrm{h}_{\mathrm{tc}}$. The consequence is that the ice shape shown in Figure 13 is worse than the one predicted with the Makkonen model. Some progress is thus expected on the use of Aupoix's model for ice accretion. Let us mention that the low $\mathrm{h}_{\mathrm{tc}}$ magnitude in the upper part of the wing even helps producing a horn at the top of the ice shape.

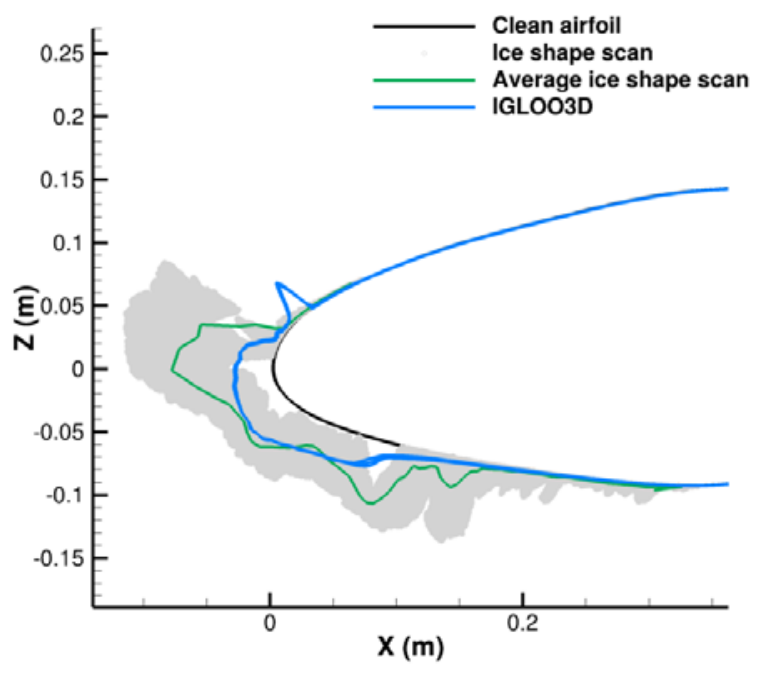

Figure 13 Ice shapes for TH2514 case (WB33 Direct Appendix C midspan) test-cases, computations with classical $\rho_{\text {ice }}$ model

Finally, there is a significant difference between the recovery temperature calculated with Aupoix's model and the one usually employed with the Makkonen model:

$T_{r}=T\left(1+\frac{\gamma-1}{2} r M^{2}\right)$, where $r=P r^{1 / 3}$

where the static temperature is $T$, the Mach number is $M, r$ is the recovery factor (here expressed in turbulent regime), which is linked to the Prandtl number Pr.

The recovery temperature predicted using Aupoix's model is significantly larger, as shown by Figure 14. It is even higher than the free-stream total temperature. This is certainly due to the fact that the turbulent Prandtl number is corrected and increased in the vicinity of the wall by the roughness effects. A more detailed study of the problem will have to be carried out in the near future.

To conclude, the use of Aupoix's model was not very successful on the SUNSET2 database. But it is a difficult database to deal with, especially because of the large sweep angle. It will be interesting to investigate straight-wing cases (e.g. from the SUNSET1 database) to improve the input characterization (laminar region, characterization of $k_{s}$ for example) and identify possible model improvements. Regarding the SUNSET2 database, a second step will be to use roughness parameters characterized in warmer icing conditions, for example, in the most studied TH2514 case. 


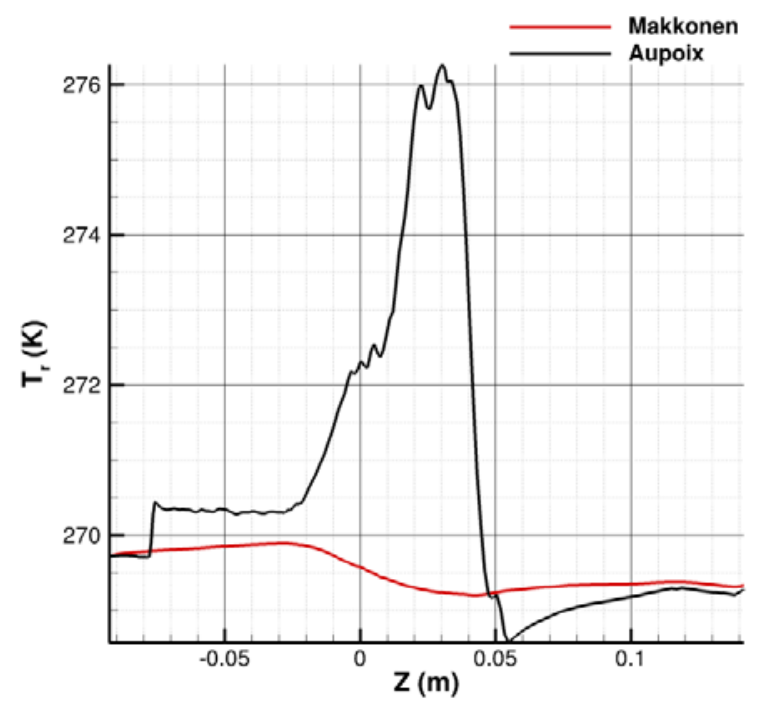

Figure 14 TH2514 case: recovery temperature

\section{Conclusion}

The ONERA's 3D icing suite, IGLOO3D, was assessed against some test-cases of the SUNSET2 database. Ice accretion was thus simulated on swept-wings tested at NASA's icing wind-tunnel IRT during the SUNSET2 program.

The investigated test-cases were primarily cases for which the spanwise ice structure is weak (small scallops or no scallop) because IGLOO3D is not expected to predict scallop ice shapes. The code does not allow multi-layer computations. Instead, only "predictor" computations around the clean airfoil are possible, to date. Therefore, some key phenomena can not be modelled. For instance, if the retroaction of the ice growth on the droplet trajectories is not modelled, the shadowing effect of spanwise structures on droplet trajectories cannot be captured. IGLOO3D is expected to allow multilayer computations in a near future.

The first "predictor" computations produced some promising results. First, a very good agreement was obtained between the aerodynamic measurements and computations. For the rime cases, the agreement between IGLOO3D, LEWICE3D and the experiments was rather good, as long as the ice density was adjusted to $450 \mathrm{~kg} / \mathrm{m}^{3}$. Some discrepancies were identified between LEWICE3D and IGLOO3D on slightly warmer cases, for which IGLOO3D predicted strictly no runback. The laminar-turbulent transition modelling and the roughness size modelling may be two important reasons for the discrepancy. For the warmest cases, IGLOO3D and LEWICE3D both predict glaze ice. Moreover, the agreement with the average ice shape is not so bad. For this case, it seems that it is better to employ the usual ice density rather than the manually adjusted bulk density. Further investigations will have to be made regarding bulk density models which would be suitable for this swept-wing database.

Finally, some first tests were performed with evolved heat transfer computations. Aupoix's RANS rough-wall model was assessed. A preliminary assessment of the model inputs was made by postprocessing the experimental ice shapes. But it seems that the model overestimates the convective heat transfer at the separation line, which tends to decrease the quantity of runback water. Further work Page 9 of 10 is therefore needed to better define the model inputs, and potentially adjust the model.

\section{References}

1. Broeren, A. P., Potapczuk, M. G., Lee, S., Malone, A. M., Paul, B. P., and Woodard, B. S., " Ice-Accretion Test Results for Three Large-Scale Swept-Wing Models in the NASA Icing Research Tunnel", 8th AIAA Atmospheric and Space Environments Conference, Washington D.C., AIAA 2016-3733, 2016.

2. Radenac, E., Validation of a 3D ice accretion tool on swept wings of the SUNSET2 program, 8th AIAA Atmospheric and Space Environments Conference, Washington D.C., AIAA 2016-3735, 2016.

3. Fujiwara, G.E.C., Bragg, M.B., Camello, S.C., and Lum, C., "Computational and Experimental Ice Accretions of Large Scale Swept Wings in the Icing Research Tunnel", 8th AIAA Atmospheric and Space Environments Conference, Washington D.C., AIAA 2016-3734, 2016.

4. Cambier, L., Heib, S., and Plot, S., "The ONERA elsA CFD software: input from research and feedback from industry", Mechanics\&Industry, Vol. 14, No 3, Jan. 2013, pp. 159-174

5. Makkonen, L., Heat transfer and icing of a rough cylinder, Cold regions science and technology, 10 (2), pp. 105-116 (1985).

6. Aupoix, B., Improved Heat Transfer Predictions on Rough Surfaces, International Journal of Heat and Fluid Flows, Vol. 56, pp. 160-171, doi: 10.1016/j.ijheatfluidflow.2015.07.007, 2015

7. Makkonen L, Stallabras JR, Ice accretion on cylinders and wires. National Research council of Canada, NRC Tech. Report, TR-LT-005, 1984.

8. Macklin WC, The density and structure of ice formed by accretion. Quart J Roy Meteor Soc (88):30-50, 1962.

9. Papadakis, M., Rachman, A., Wong, S.-C., Yeong, H.-W., Hung, K., and Bidwell, C., Water Impingement Experiments on a NACA 23012 Airfoil with Simulated Glaze Ice Shapes, AIAA Paper 2004-565, 2004.

10. Flack, K.A. and Schultz, M.P., Review of hydraulic roughness scales in the fully rough regime, Journal of Fluid Engineering, 132:041203,2010.

11. McClain, S.T., Vargas, M., Tsao, J.-C., Broeren, A.P. and Lee, S., Ice accretion roughness measurements and modeling, 7th European Conference for Aeronautics and Space Sciences (EUCASS), EUCASS2017-555, 2017.

12. Aupoix, B., Roughness Corrections for the $k-\omega$ Shear Stress Transport Model: Status and Proposals, Journal of Fluids Engineering, 137, 2015.

\section{Contact Information}

Emmanuel Radenac, emmanuel.radenac@onera.fr

\section{Acknowledgements}

The authors wish to acknowledge the contributions of Andy Broeren and Sam Lee who generated the ice shapes (among other collaborators in NASA Glenn Research Center) and provided experimental data for validation and cross-comparisons. The authors are also grateful to Gustavo Fujiwara (University of Washington) and Brian Woodard (University of Illinois), who provided computational 
input data. Philippe Villedieu and François Chedevergne at ONERA are also thanked for the numerous discussions about this work.

\section{Definitions/Abbreviations}

$\begin{array}{ll}\text { LWC } & \text { Liquid Water Content } \\ \text { MVD } & \text { Median Volume Diameter } \\ \text { RANS } & \text { Reynolds Averaged Navier-Stokes } \\ \boldsymbol{C}_{\boldsymbol{f}} & \text { Skin friction coefficient } \\ \boldsymbol{C p} & \text { Pressure coefficient } \\ \boldsymbol{c}_{\boldsymbol{p}} & \text { Specific heat capacity at constant } \\ \boldsymbol{h}_{\boldsymbol{t c}} & \text { pressure, J/K/kg } \\ \boldsymbol{k}_{\boldsymbol{s}} & \text { Heat transfer coefficient, W/K/m² } \\ \mathbf{M} & \text { Equivalent sand-grain roughness } \\ \mathbf{P} & \text { height, m } \\ \mathbf{P r} & \text { Mach number } \\ \mathbf{r} & \text { Pressure, Pa } \\ \text { St } & \text { Prandtl number } \\ \mathbf{T} & \text { Recovery factor } \\ \mathbf{u , ~ V} & \text { Stanton number } \\ \boldsymbol{\beta} & \text { temperature, K } \\ \Delta \boldsymbol{t} & \text { velocity, m/s } \\ \boldsymbol{\theta} & \text { Collection efficiency } \\ \boldsymbol{\mu} & \text { Exposure time to icing cloud, s } \\ \boldsymbol{\rho} & \text { Momentum thickness, m } \\ & \text { Dynamic viscosity, Pa.s } \\ & \text { Density, kg/m }{ }^{3} \\ & \end{array}$

\section{Subscripts}

ice

$\mathbf{k}$

$\mathbf{r}$

t

$\tau$
Related to the ice material

Roughness

Recovery

Turbulent

Friction 